\title{
Projeto otimizado e análise por elementos finitos de um motor a relutância variável
}

\section{8/6 tetrafásico}

\author{
Optimized design and finite element analysis of a four-phase 8/6 switched reluctance motor \\ Diseño optimizado y análisis de elementos finitos de un motor de reluctancia variable 8/6 de cuatro
}

fases

Recebido: 12/01/2022 | Revisado: 20/01/2022 | Aceito: 21/01/2022 | Publicado: 22/01/2022

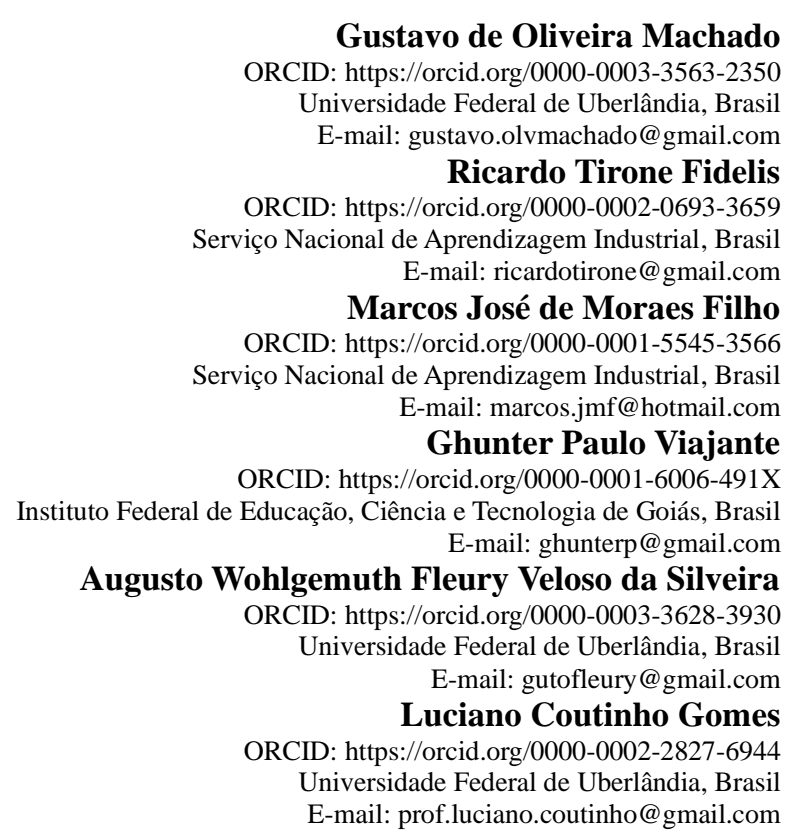

\begin{abstract}
Resumo
O motor a relutância variável (MRV) tem sido considerado uma alternativa viável para substituir os motores elétricos clássicos em aplicações que demandam acionamentos com velocidades variáveis. Este motor é robusto, dispõe de uma construção simples e tem a vantagem de possuir um rotor que não necessita de enrolamentos ou ímãs permanentes para operar. Neste trabalho, um MRV 8/6 tetrafásico é projetado a fim de substituir um motor de indução trifásico (MIT), utilizando a mesma carcaça disponível. Na metodologia adotada para o projeto, os dados mecânicos da carcaça do MIT são utilizados como parâmetros iniciais para o cálculo das dimensões do MRV. A escolha dos ângulos dos arcos dos polos do MRV é otimizada através da análise por elementos finitos. Além disso, as simulações realizadas via elementos finitos possibilitam a visualização da distribuição do fluxo magnético na estrutura do MRV e o levantamento de dados importantes como os perfis de indutância e de fluxo concatenado, e o torque do motor projetado. O maior erro relativo obtido para a densidade de fluxo magnético no núcleo do motor foi de 1,69\% e o torque resultante do MRV foi muito próximo do torque requerido inicialmente. Esses resultados apresentados validam o protótipo projetado e consolidam a metodologia de projeto utilizada.
\end{abstract}

Palavras-chave: Análise de elementos finitos; Método iterativo; Motor a relutância variável; Projeto de motor.

\begin{abstract}
The switched reluctance motor (SRM) has been considered a viable alternative to replace the classic electric motors in applications that require variable speed drives. This motor is robust, has a simple construction and the advantage of having a rotor that doesn't need windings or permanent magnets to operate. In this paper, a four-phase 8/6 SRM is designed in order to replace a three-phase induction motor (IM), using the same frame available. In the design methodology adopted, the mechanical data of the three-phase IM frame are used as initial parameters for calculus of the SRM dimensions. The choice of the SRM's pole arc angles is optimized by the finite elements analysis (FEA). Furthermore, the FEA simulations allows the visualization of the magnetic flux distribution in the SRM structure and the gathering of important data such as the inductance and flux linkage profiles, and also the designed motor's torque. The largest relative error obtained for the magnetic flux density in the motor core was $1.69 \%$ and the SRM's resulting
\end{abstract}


torque was very close to the one required initially. The presented results validate the designed prototype and consolidate the design methodology used.

Keywords: Finite element analysis; Iterative method; Switched reluctance motor; Motor design.

\section{Resumen}

El motor de reluctancia variable (MRV) se ha considerado una alternativa viable para reemplazar los motores eléctricos clásicos en aplicaciones que demandan variadores de velocidad. Este motor es robusto, tiene una construcción simple y tiene la ventaja de tener un rotor que no necesita bobinados ni imanes permanentes para funcionar. En este trabajo se diseña un MRV 8/6 de cuatro fases para reemplazar un motor de inducción trifásico (MIT), utilizando la misma carcasa disponible. En la metodología adoptada para el proyecto, los datos mecánicos de la vivienda MIT se utilizan como parámetros iniciales para el cálculo de las dimensiones del MRV. La elección de los ángulos de arco polar MRV se optimiza a través del análisis de elementos finitos. Además, las simulaciones realizadas mediante elementos finitos permiten la visualización de la distribución del flujo magnético en la estructura MRV y la recopilación de datos importantes, como los perfiles de enlace de inductancia y flujo, y el par motor diseñado. El mayor error relativo obtenido para la densidad de flujo magnético em el núcleo del motor fue de $1,69 \%$ y el par resultante del MRV estuvo muy cerca del par requerido inicialmente. Estos resultados presentados validan el prototipo diseñado y consolidan la metodología de diseño utilizada.

Palabras clave: Análisis de elementos finitos; Método iterativo; Motor de reluctancia variable; Diseño del motor.

\section{Introdução}

A máquina a relutância variável (MaRV) é uma máquina elétrica especial de polos salientes na qual o torque é produzido pela tendência do rotor em se movimentar para a posição de alinhamento dos polos, onde a relutância é mínima. A MaRV apresenta diversas vantagens, como: simplicidade, robustez, ausências de bobinas e ímãs permanentes no rotor, alta densidade de torque, eficiência elevada, facilidade para operar em altas velocidades e em velocidades variáveis, tolerância a falta de fase, entre outras (Bilgin \& Emadi, 2018).

Apesar dessas vantagens, a MaRV teve um desenvolvimento tardio em relação aos outros tipos de máquinas, devido à dependência de conversores eletrônicos e à necessidade de se conhecer em tempo real a posição do rotor para realizar o acionamento das fases. Todavia, nas últimas décadas, com as evoluções da eletrônica de potência, das técnicas de controle e dos microcontroladores, há aplicações em que a MaRV tem se tornado cada vez mais viável para substituir as máquinas elétricas convencionais de indução, síncrona e de corrente contínua (Ahn \& Lukman, 2018; Pyrhonen et al., 2013). Essas aplicações são, em geral, as que demandam acionamentos com velocidades variáveis, como no caso dos geradores eólicos, que são submetidos às diversas condições climáticas e devem se adequar a velocidade momentânea do vento (Rahmanian et al., 2017; Viajante et al., 2018; Lu et al., 2020).

A MaRV também tem se tornado uma ótima opção para o setor automotivo. Por não necessitar de ímãs permanentes e apresentar uma ampla faixa de velocidade com potência constante, grandes empresas têm escolhido o motor a relutância variável (MRV) para realizar a tração de seus veículos elétricos e híbridos (Bilgin \& Emadi, 2018; Chiba \& Kiyota, 2015). Aplicações do MRV são encontradas também no setor aeronáutico, onde a confiabilidade e a segurança do projeto são fatores essenciais. Nesse setor, o MRV tem se tornado atrativo por possuir uma menor taxa de falhas e um maior tempo médio entre falhas do que outros motores disponíveis no mercado (Castellini et al., 2015). Em pequenas parcelas, o MRV ainda pode ser utilizado para acionar cargas como: máquinas de mineração, bombas centrífugas, compressores de ar, máquinas de lavar roupas, aspiradores de pó e ventiladores (Bilgin \& Emadi, 2018).

Visto o alto potencial técnico e econômico do MRV, a proposta deste trabalho é apresentar o projeto de um motor a relutância variável com o objetivo de substituir um motor de indução trifásico (MIT). A escolha do MRV se justifica pelo custo-benefício de sua construção, pois é um motor robusto e possível de ser fabricado de maneira simples, com baixo consumo de materiais. Além disso, como o MRV deve ser inerentemente acionado com conversor eletrônico, o mesmo pode ser posteriormente utilizado para acionar cargas com velocidades variáveis (Bilgin \& Emadi, 2018). 
Para diminuir os custos totais do projeto do MRV, a mesma carcaça disponível do MIT pode ser aproveitada. A utilização de uma carcaça comercial para abrigar o MRV é um fator econômico muito vantajoso, pois sendo um produto originado de uma linha de produção em larga escala, seu custo é reduzido. Com esse objetivo, é adotada como referência principal a metodologia de projeto desenvolvida por Vijayraghavan (2001), na qual as dimensões mecânicas da carcaça comercial são utilizadas como parâmetros iniciais para o cálculo das dimensões do MRV. Segundo Vijayraghavan (2001), essa metodologia é vantajosa porque não necessita que o projetista tenha uma vasta experiência prévia em projetos de MRVs, em comparação com outros procedimentos, que requerem conhecimento empírico para determinação de muitas constantes ao longo do dimensionamento do motor.

O método de projeto empregado neste trabalho é iterativo e foi adaptado do original, substituindo o cálculo analítico da indutância e do torque pela simulação computacional com aplicação do método de elementos finitos (MEF), visando obter resultados mais precisos. O software de elementos finitos utilizado é o Finite Element Method Magnetics (FEMM), versão 4.2, gratuito e de código aberto (Meeker, 2020). Na interface desse software é feita a visualização gráfica da distribuição de fluxo magnético nas lâminas do MRV e também são levantadas as curvas de indutância e fluxo magnético concatenado, o que possibilita o cálculo do torque médio do motor para validação do projeto.

\section{Metodologia}

\subsection{Aspectos construtivos e operacionais do MRV}

O MRV possui uma construção simples, com polos salientes no estator e no rotor. O estator é formado por material ferromagnético e possui bobinas de cobre enroladas em cada polo que, quando conectadas, constituem os enrolamentos de fases do motor. O rotor também é formado por material ferromagnético, porém não possui nenhum tipo de enrolamento ou ímã permanente, o que contribui para que o MRV seja robusto e capaz de suportar com segurança operações em altas velocidades (Bilgin \& Emadi, 2018).

O princípio de operação do MRV é baseado na geração de torque a partir da variação da relutância (Jiang, 2016). Quando as bobinas do estator são energizadas, é produzido um campo magnético no estator, que faz com que polos diametralmente opostos do rotor tendam a se movimentar em direção aos polos do estator onde há geração do campo, para minimizar a relutância do circuito magnético. Quando a posição de relutância mínima é alcançada, as forças magnéticas tendem a manter o rotor nessa posição de equilíbrio. Portanto, as bobinas de outra fase devem ser excitadas antes de se atingir o alinhamento completo, para que o rotor continue a se mover de forma contínua.

O valor da corrente de excitação de fase tem relação direta com a intensidade do campo magnético gerado, e consequentemente, afeta as características do fluxo magnético concatenado, da indutância e do torque do MRV. Ao mesmo tempo, devido a estrutura duplamente saliente do MRV, essas características são também dependentes da posição do rotor. Para garantir sempre um torque positivo, é importante que as fases do MRV sejam acionadas em sequência sempre no início da região de indutância crescente. Por esse motivo, geralmente é feita a inserção de um encoder acoplado ao eixo do MRV a fim de se obter a posição do rotor em tempo real, para controlar o acionamento das fases de forma adequada (Krishnan, 2001). Além disso, para evitar que os valores das correntes nas fases ultrapassem os limites de suportabilidade dos condutores e os limites térmicos da máquina, normalmente é feito um controle por histerese de corrente através de chaveamentos em um conversor de ponte assimétrica, conforme descrito por Howey e Li (2018).

As dimensões das lâminas do estator e do rotor do MRV 8/6 estão representadas na Figura 1. O projeto do MRV consiste em determinar essas dimensões a fim de obter uma geometria final que resulte na performance esperada para o motor, pois cada uma dessas dimensões influencia nas características do MRV. 
Figura 1. Geometria do MRV 8/6 com destaque de suas principais dimensões.

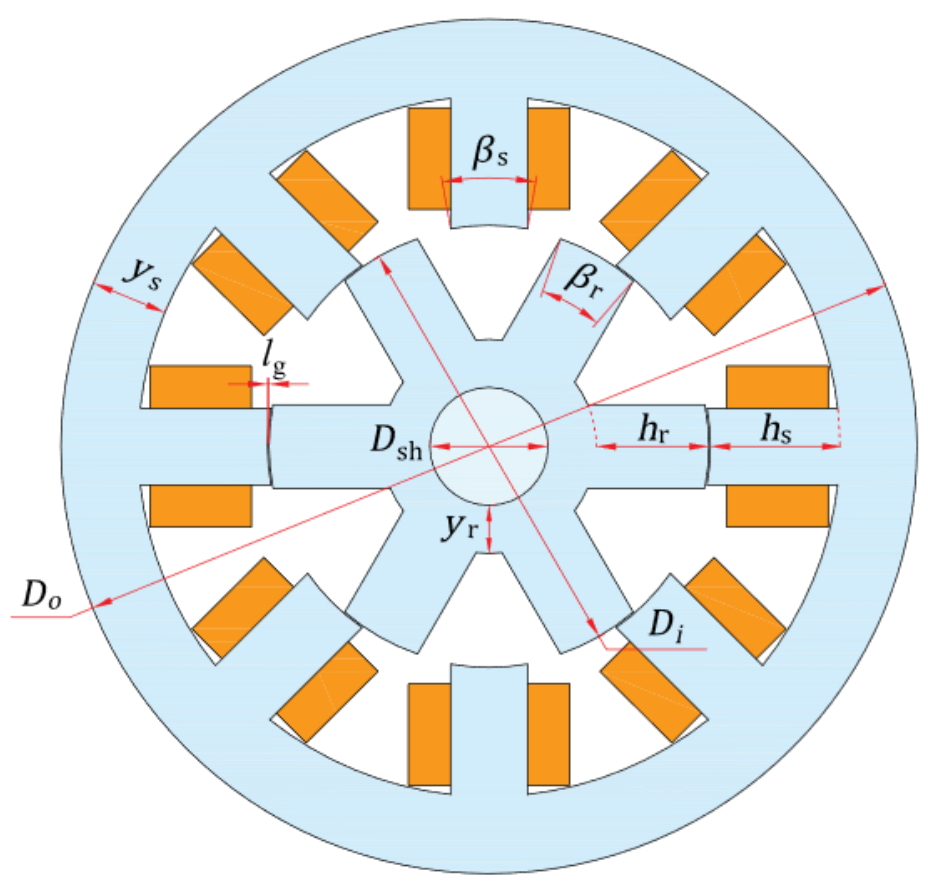

Fonte: Elaboração própria.

\subsection{Considerações iniciais sobre a metodologia de projeto utilizada}

Embora diferentes procedimentos de projetos de MRVs tenham sido concebidos nos últimos anos (Mamede et al., 2020), a metodologia desenvolvida por Vijayraghavan (2001) é preferível devido aos objetivos desse trabalho, por possibilitar o dimensionamento do MRV a fim de abrigá-lo em uma carcaça comercial, conforme comentado na introdução.

Essa metodologia de projeto foi inicialmente proposta com base na utilização de cálculos analíticos. O projeto se inicia pela escolha de uma carcaça comercial para abrigar o MRV e avança para a seleção das demais dimensões de maneira metódica (Vijayraghavan, 2001). Os cálculos dos diâmetros externos e internos do estator $D_{o}$ e $D_{i}$, do diâmetro do eixo $D_{s h}$ e do comprimento da pilha de lâminas $L$ são feitos diretamente a partir das dimensões mecânicas da carcaça. As demais dimensões do MRV são determinadas após a seleção dos ângulos dos arcos dos polos do estator $\beta s$ e do rotor $\beta r$. A escolha adequada desses ângulos é essencial para um bom projeto do motor, pois os mesmos influenciam de forma significativa o perfil de indutância da máquina, e consequentemente, afetam o controle e o acionamento das fases (Vijayraghavan, 2001).

A seleção dos ângulos $\beta_{s}$ e $\beta r$ requer um procedimento iterativo para obtenção da combinação de ângulos que fornece o torque requerido com as menores perdas, uma vez que existem diversas combinações possíveis que atendem às restrições necessárias para garantir a partida própria da máquina e um perfil de torque adequado (Krishnan, 2001; Miller, 2001; Vijayraghavan, 2001). No procedimento proposto por Vijayraghavan (2001), o número de combinações possíveis é ainda limitado por mais duas restrições adicionais, que serão apresentadas posteriormente na subseção 2.4 .2 juntamente com outros detalhes do projeto.

Em Vijayraghavan (2001), os diversos MRVs resultantes de cada combinação de ângulos possíveis são analisados a partir do torque médio produzido, que é determinado através de um método analítico que foi desenvolvido para estimar os valores das indutâncias nas posições alinhada e desalinhada do rotor, $\theta_{a}$ e $\theta d$, respectivamente. Vijayraghavan (2001) propõe esse método de acordo com a teoria de circuitos magnéticos e divide a geometria do MRV em diversos tubos contendo linhas de fluxo magnético, para calcular a relutância e a indutância associadas a cada tubo. Ao final do procedimento, soma-se as 
indutâncias individuais dos tubos para obter a indutância total da fase. A partir dos valores obtidos das indutâncias alinhada $L a$ e desalinhada $L d$, os fluxos $\lambda_{a}$ e $\lambda_{d}$ para as posições alinhada e desalinhada, e as coenergias magnéticas $W_{a}^{\prime}$ e $W^{\prime} d$ correspondentes podem também ser determinados. Com os valores das coenergias, o torque médio do MRV Tm é calculado.

Embora o método analítico citado seja prático e de baixo custo computacional, as aproximações trigonométricas feitas para calcular os caminhos, as áreas e as relutâncias dos tubos de fluxo podem gerar alguns erros que, quando acumulados, influenciam na confiabilidade do resultado final, conforme relatado por Vijayraghavan (2001). Além disso, as equações desenvolvidas para os cálculos analíticos das indutâncias não são genéricas, pois a distribuição das linhas de fluxo é diferente para cada topologia de MRV, de acordo com o número de polos. Então, caso o projetista opte por uma topologia diferente da 8/6, o mesmo deve desenvolver as equações com base na topologia que for escolhida, o que claramente é uma grande desvantagem.

Visto isso, o presente trabalho também propõe uma adaptação da metodologia desenvolvida por Vijayraghavan (2001), através da substituição do cálculo analítico das indutâncias pela obtenção dos fluxos por meio de simulações com elementos finitos. Como o cálculo do torque médio depende apenas dos valores das coenergias geradas para as posições alinhada e desalinhada, então após a aplicação das restrições sugere-se simular as geometrias dos MRVs possíveis e obter os valores das coenergias, o que possibilita a determinação dos torques médios de cada MRV para a escolha otimizada da geometria do motor que fornece os melhores resultados.

Apesar das simulações com o MEF exigirem um custo computacional maior do que o método analítico, os resultados obtidos são mais precisos, pois com o MEF os efeitos devidos às não-linearidades e à saturação magnética do MRV são considerados (Watthewaduge et al., 2020). Além disso, como o MRV possui simetria axial, pode-se utilizar um modelo bidimensional (2D) para reduzir os tempos de simulação. Em suma, como atualmente a capacidade de processamento dos computadores permite ao projetista simular o motor e obter dados de forma muito rápida, o custo-benefício da substituição do método analítico pelo MEF é vantajoso.

A Figura 2 é apresentada a fim de ilustrar o procedimento realizado para o cálculo do torque médio com o método adaptado. As curvas de fluxo magnético em função da corrente são obtidas através de simulações com o MEF. Os valores das áreas abaixo das curvas de fluxo para as posições alinhada e desalinhada são correspondentes às coenergias $W_{a}^{\prime}$ e $W_{d}^{\prime}$, respectivamente. Os valores dessas coenergias são calculados através das integrais dos fluxos concatenados em relação à corrente para as duas posições fixas, conforme as Equações (1) e (2). A área entre as duas curvas representa o trabalho realizado por ciclo do motor $\delta W_{m}$ e é calculado através da diferença entre os valores obtidos para as coenergias através da Equação (3). A partir do resultado obtido para $\delta W_{m}$ e dos números de polos do estator e do rotor, $N_{s}$ e $N_{r}$ respectivamente, o torque médio do MRV pode então ser determinado através da Equação (4) (Vijayraghavan, 2001; Krishnan, 2001). 
Figura 2. Fluxo magnético concatenado versus corrente de excitação para as posições alinhada e desalinhada do rotor.

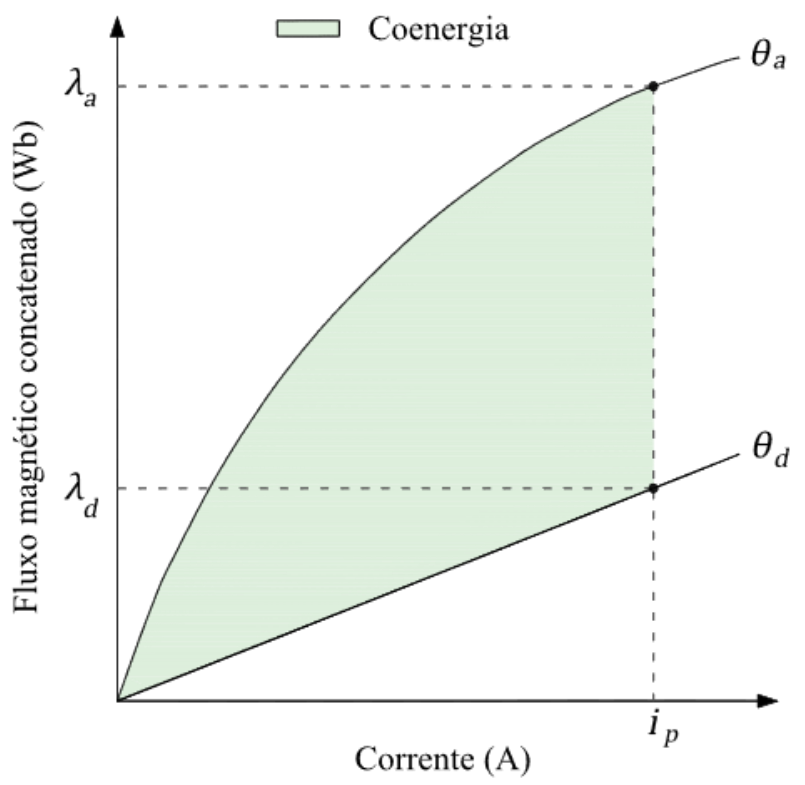

Fonte: Elaboração própria.

$$
\begin{gathered}
W_{a}^{\prime}=\left.\int_{0}^{i_{p}} \lambda(\theta, i) d i\right|_{\theta_{a}=\text { constante }} \\
W_{d}^{\prime}=\left.\int_{0}^{i_{p}} \lambda(\theta, i) d i\right|_{\theta_{d}=\text { constante }} \\
\delta W_{m}=W_{a}^{\prime}-W_{d}^{\prime} \\
T_{m}=\frac{\delta W_{m} \times N_{s} \times N_{r}}{4 \pi}
\end{gathered}
$$

Para se obter uma solução precisa através da aplicação do MEF, é necessário que a malha de elementos finitos possua uma quantidade significativa de nós e que os elementos utilizados sejam adequados de acordo com a geometria do problema a ser resolvido. Pode-se dizer que quanto mais refinada for a malha, ou seja, quanto maior for a quantidade de nós, maior será a precisão da resposta obtida através da aplicação do método. No entanto, vale ressaltar que a geração de malhas extremamente refinadas pode aumentar drasticamente o tempo de simulação computacional, portanto, cabe ao aplicador do método escolher um tamanho adequado para a malha de elementos finitos (Hutton, 2004; Oliveira, 2013; Watthewaduge et al., 2020).

A Figura 3 ilustra a malha de elementos finitos gerada no software FEMM para a simulação do MRV 8/6 projetado neste trabalho. Na sequência, a Tabela 1 apresenta as principais propriedades definidas no FEMM para construção dessa malha de elementos finitos. Nota-se na Figura 3 e na Tabela 1 que foram utilizados elementos de tamanhos diferentes para discretização do domínio do problema. Nas regiões do núcleo do MRV utilizou-se elementos de tamanhos menores, ou seja, a malha foi refinada nessas partes, a fim de se alcançar maior precisão na solução. Já nas regiões preenchidas pelo ar foi possível utilizar elementos maiores, pois o ar possui uma baixa permeabilidade magnética e, portanto, não exerce interferência significativa no desempenho do motor. 
Figura 3. Malha de elementos finitos gerada no FEMM para a simulação do MRV 8/6.

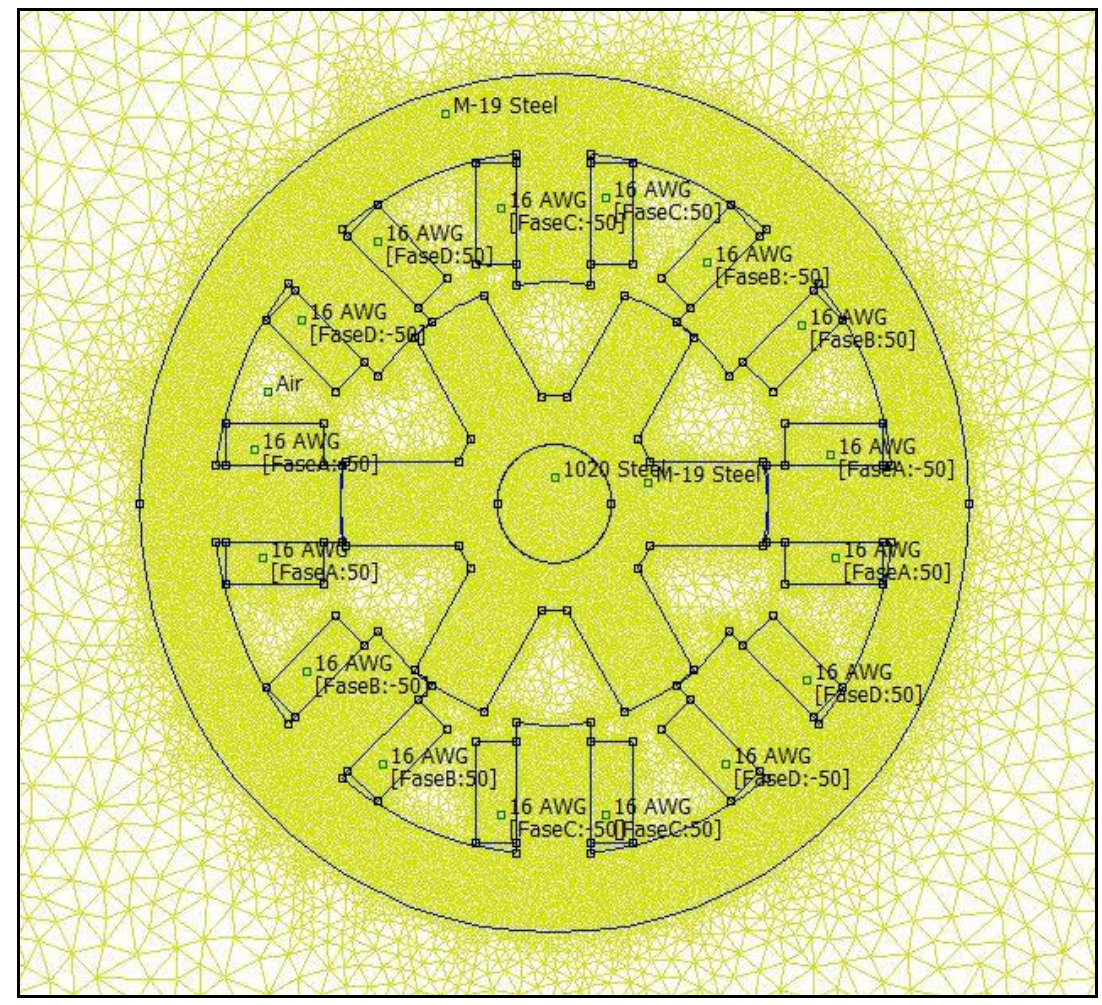

Fonte: Elaboração própria.

Tabela 1. Propriedades da malha de elementos finitos gerada no FEMM.

\begin{tabular}{ll}
\hline Propriedade & Especificação \\
\hline Tipo da malha & Triangular \\
Quantidade total de nós & 54131 \\
Tamanho máximo dos elementos nas regiões do núcleo do MRV & $0,8 \mathrm{~mm}$ \\
Tamanho máximo dos elementos nas regiões preenchidas pelo ar & $2 \mathrm{~mm}$ \\
Ângulo mínimo para triangulação & $30^{\circ}$ \\
\hline
\end{tabular}

Fonte: Elaboração própria.

\subsection{Requisitos do projeto e parâmetros iniciais}

\subsubsection{Características do MIT de referência}

O MRV projetado deve ser capaz de entregar características de acionamento semelhantes àquelas que o MIT a ser substituído entrega para uma carga nominal, com aproveitamento da mesma carcaça disponível. As principais características de operação desse MIT são obtidas através do catálogo técnico disponível pela fabricante WEG S.A. (2021) e estão apresentadas na Tabela 2. Todas as dimensões da carcaça e os demais dados mecânicos do MIT utilizados para esse projeto podem ser obtidos também através do catálogo técnico em WEG S.A. (2021). 
Tabela 2. Características de placa do motor de indução trifásico.

\begin{tabular}{ll}
\hline Parâmetro & Valor \\
\hline Fabricante & WEG \\
Modelo & W22 IR3 Premium \\
Carcaça & L90S \\
Potência de saída & $2,2 \mathrm{~kW}-3 \mathrm{hp}$ \\
Tensão nominal & $220 \mathrm{~V}$ \\
Corrente nominal & $7,82 \mathrm{~A}$ \\
Velocidade nominal & $3470 \mathrm{rpm}$ \\
Torque nominal & $6,061 \mathrm{~N} . \mathrm{m}$ \\
Rendimento & $86,5 \%$ \\
\hline Fator de potência & 0,85 \\
\hline
\end{tabular}

Fonte: Elaboração própria.

\subsubsection{Configuração de polos do MRV}

Além das condições de operação e das dimensões da carcaça do MIT, outro fator importante para se considerar no início do projeto do MRV é a determinação do número de polos do estator e do rotor. Neste caso, optou-se pela topologia tetrafásica 8/6, isto é, $N_{s}=8$ e $N_{r}=6$. Essa escolha se fundamenta no fato de que a topologia 8/6 proporciona menos ondulação de torque em comparação com outras topologias comuns, como a 6/4 ou a 4/2. Explicações mais detalhadas sobre as vantagens e desvantagens de cada configuração de polos podem ser encontradas no trabalho desenvolvido por Mamede (2016).

\subsubsection{Material magnético}

O aço silício de grão não orientado M-19 foi escolhido para formar as lâminas do estator e do rotor do MRV 8/6. As lâminas possuem $0,5 \mathrm{~mm}$ de espessura e são prensadas umas às outras. O aço M-19 é um material magnético de alta qualidade e resistência, possui bons valores de permeabilidade e têm baixas perdas magnéticas. Além disso, esse material está disponível na biblioteca do FEMM e será empregado na simulação magnética do motor projetado neste trabalho.

\subsection{Projeto do MRV}

\subsubsection{Dimensões iniciais}

A International Electrotechnical Commission (IEC) fixa dimensões padronizadas para todos os motores elétricos fabricados internacionalmente. A principal dimensão para padronização das montagens dos motores é a altura do plano da base ao centro da ponta do eixo, representada pela letra $H$ no catálogo técnico disponível pela WEG S.A. (2021). O valor da altura $H$ para a carcaça L90S é de 90 mm e o diâmetro do eixo do MIT é de 24 mm (WEG S.A., 2021).

De acordo com Vijayraghavan (2001), a primeira dimensão do MRV a ser determinada é o diâmetro externo do estator, que pode ser obtido substituindo o valor de $H$ na Equação (5). A subtração de três milímetros do valor de $H$ na Equação (5) é feita para descontar a altura do pé da máquina usado na montagem.

$$
D_{o}=(H-3) \times 2
$$

O diâmetro interno do estator é inicialmente adotado como sendo igual ao valor de $H$, podendo ser alterado posteriormente. Já o diâmetro do eixo do MRV é o mesmo do eixo do MIT para a carcaça L90S (24 mm). O comprimento da 
pilha de lâminas pode ser inicialmente escolhido para ser igual à distância entre os orifícios de montagem, o que corresponde à medida $B$ apresentada no catálogo técnico em WEG S.A. (2021). O valor de $B$ para a carcaça L90S é de $100 \mathrm{~mm}$. Como o torque médio do MRV é diretamente proporcional ao comprimento $L$, segundo Vijayraghavan (2001), o valor de $L$ deve ser sempre reduzido quando o torque resultante extrapolar em grande parcela o torque requerido pelo motor. Dessa forma, observou-se em simulações preliminares via MEF a necessidade de uma redução de $15 \%$ do valor inicial proposto, resultando em $L=85 \mathrm{~mm}$.

Embora fosse possível extrair mais potência do MRV se o mesmo tivesse o comprimento axial máximo possível para a carcaça utilizada $(100 \mathrm{~mm})$, o objetivo do projeto é manter as características de acionamento do MIT. Além disso, com um comprimento menor, o espaço vazio no interior da carcaça aumenta, o que favorece o fluxo de ar para reduzir as elevações de temperatura durante a operação do motor.

\subsubsection{Determinação dos ângulos dos polos}

Para a escolha dos ângulos dos polos do estator e do rotor, há várias combinações possíveis que respeitam as três restrições impostas explicadas nas referências clássicas de projetos de MRVs (Krishnan, 2001; Miller, 2001). Essas três restrições são brevemente apresentadas na sequência.

1) $O$ ângulo do polo do estator deve ser sempre menor que o ângulo do polo do rotor.

$$
\beta_{s}<\beta_{r}
$$

2) $O$ ângulo do polo do estator deve ser maior que o ângulo de condução de energia $\varepsilon$ para garantir que ao ser acionado o motor tenha torque de partida para qualquer posição do rotor.

$$
\beta_{s}>\varepsilon=\frac{2 \pi}{\frac{N_{s}}{2} \times N_{r}}
$$

Substituindo $N_{s}=8$ e $N_{r}=6$ no lado direito da Inequação (7), obtém-se $\varepsilon=15^{\circ}$ para a topologia $8 / 6$ escolhida para esse projeto.

3) $O$ ângulo do polo do estator deve ser menor que o ângulo entre os cantos de polos do rotor adjacentes, caso contrário haverá sobreposição de polos na posição desalinhada.

$$
\beta_{s}<\frac{2 \pi}{N_{r}}-\beta_{r}
$$

As três condições descritas nas Inequações (6), (7) e (8) delimitam o triângulo ABC ilustrado na Figura 4, que representa todas as combinações possíveis entre $\beta_{s}$ e $\beta r$ para o projeto do MRV. 
Figura 4. Triângulo de possibilidades para os ângulos dos polos do MRV 8/6.

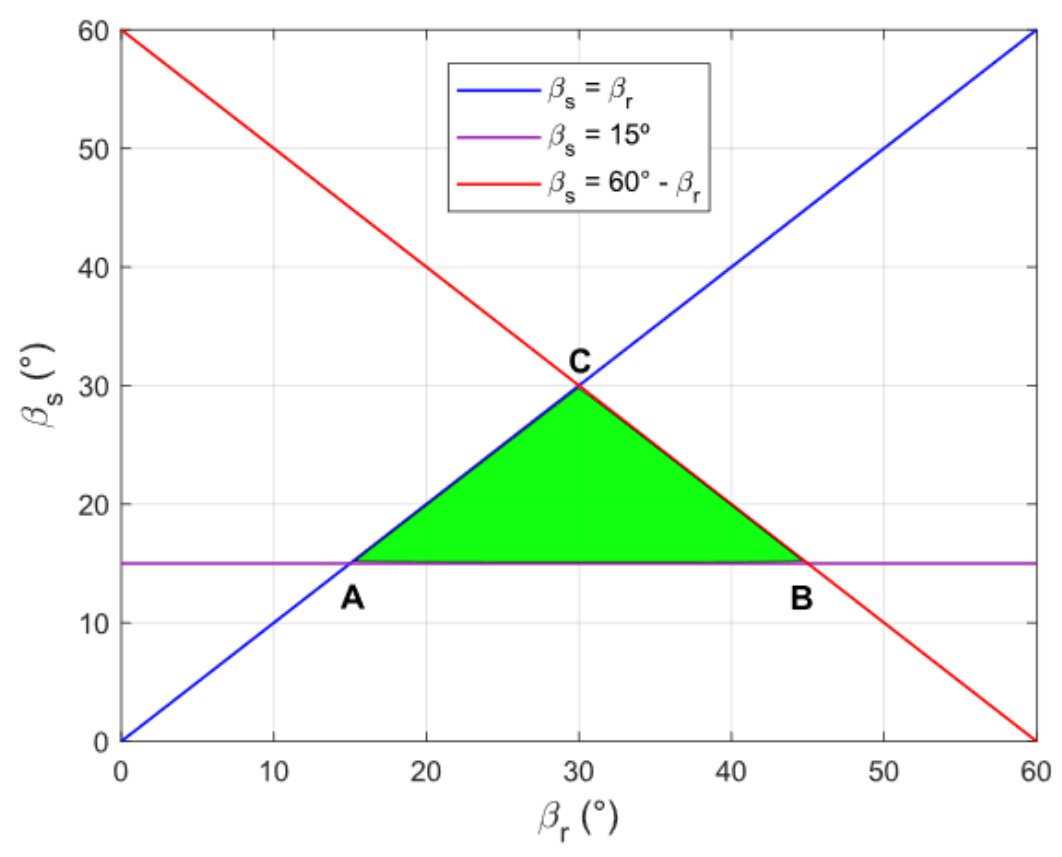

Fonte: Elaboração própria.

O triângulo ABC da Figura 4 revela que há 196 combinações admissíveis de $\beta_{s}$ e $\beta r$ para o projeto do motor, considerando apenas valores inteiros para os ângulos. Para diminuir essa quantidade de combinações possíveis, são recomendadas mais duas restrições em Vijayraghavan (2001).

A primeira restringe a diferença dos valores dos ângulos $\beta_{s}$ e $\beta r$ para $2^{\circ}$, justificando que há uma perda expressiva de torque por volume de ferro quando se utiliza diferenças maiores (Vijayraghavan, 2001). Com essa restrição, o número de combinações possíveis é reduzido para 27. A segunda limitação diz respeito à folga $C l$ que deverá haver entre enrolamentos consecutivos para garantir o perfeito funcionamento do motor, com segurança de que não haverá contato interno entre as bobinas gerando curto-circuito. Segundo Vijayraghavan (2001), essa folga deve ser sempre maior que três milímetros.

A partir dessas restrições, é feito todo o processo de cálculo das demais dimensões do MRV e dos enrolamentos para cada combinação de ângulos dentre as 27 restantes, a fim de verificar para cada uma se o torque resultante e o enrolamento projetado atendem aos requisitos do projeto. O fluxograma apresentado na Figura 5 ilustra todas as etapas desse procedimento. Seguindo o método iterativo apresentado no fluxograma da Figura 5, foram projetados 27 motores, correspondentes às diferentes combinações de ângulos restantes. A combinação 1 têm $\beta_{s}=16^{\circ}$ e $\beta r=17^{\circ}$, a combinação 2 têm $\beta_{s}=16^{\circ}$ e $\beta r=18^{\circ}$, a combinação 3 têm $\beta_{s}=17^{\circ}$ e $\beta r=18^{\circ}$, e assim por diante até a combinação 27 , correspondente à $\beta s=29^{\circ}$ e $\beta_{r}=30^{\circ}$. 
Figura 5. Fluxograma das etapas de projeto do MRV.

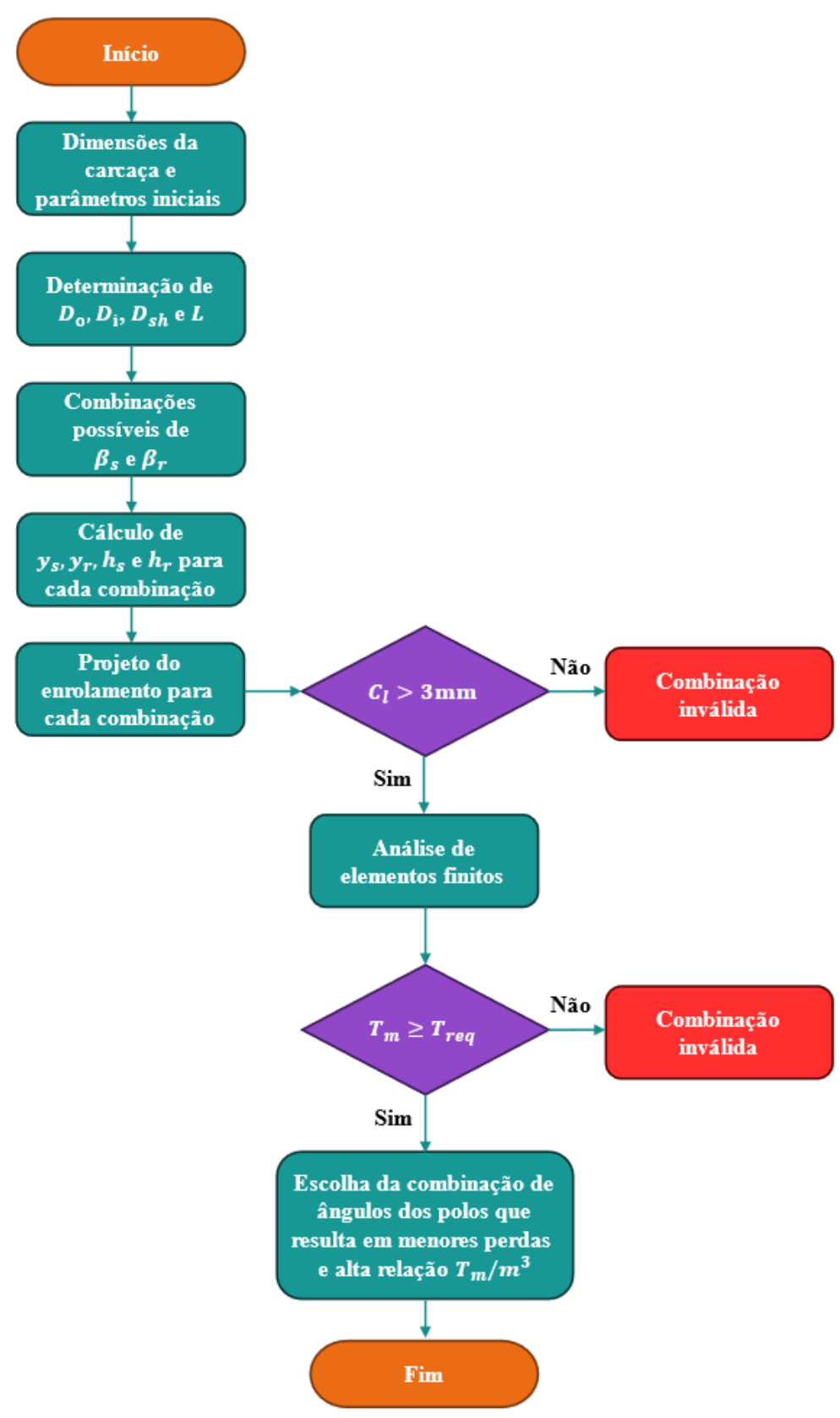

Fonte: Elaboração própria.

Os valores obtidos para as folgas entre os enrolamentos para todas as 27 combinações de ângulos analisadas estão apresentados no gráfico da Figura 6. As equações utilizadas para calcular as dimensões do MRV e projetar os enrolamentos serão mostradas posteriormente nas subseções 2.4.3 e 2.4.4.

A partir da Figura 6, elimina-se todas as combinações de ângulos que geram folgas menores que três milímetros, restando apenas as combinações de 1 a 10. Para escolher a melhor combinação entre as dez possibilidades restantes, é realizada uma análise mais aprofundada, na qual são calculados o torque médio, o torque por volume, o número de espiras e as perdas no cobre para cada uma das combinações restantes. Para isso, os dez motores foram simulados no FEMM, o que permitiu a obtenção dos dados da Tabela 3 para comparação e escolha da melhor opção. 
Figura 6. Folga entre os enrolamentos para diferentes combinações de ângulos dos polos.

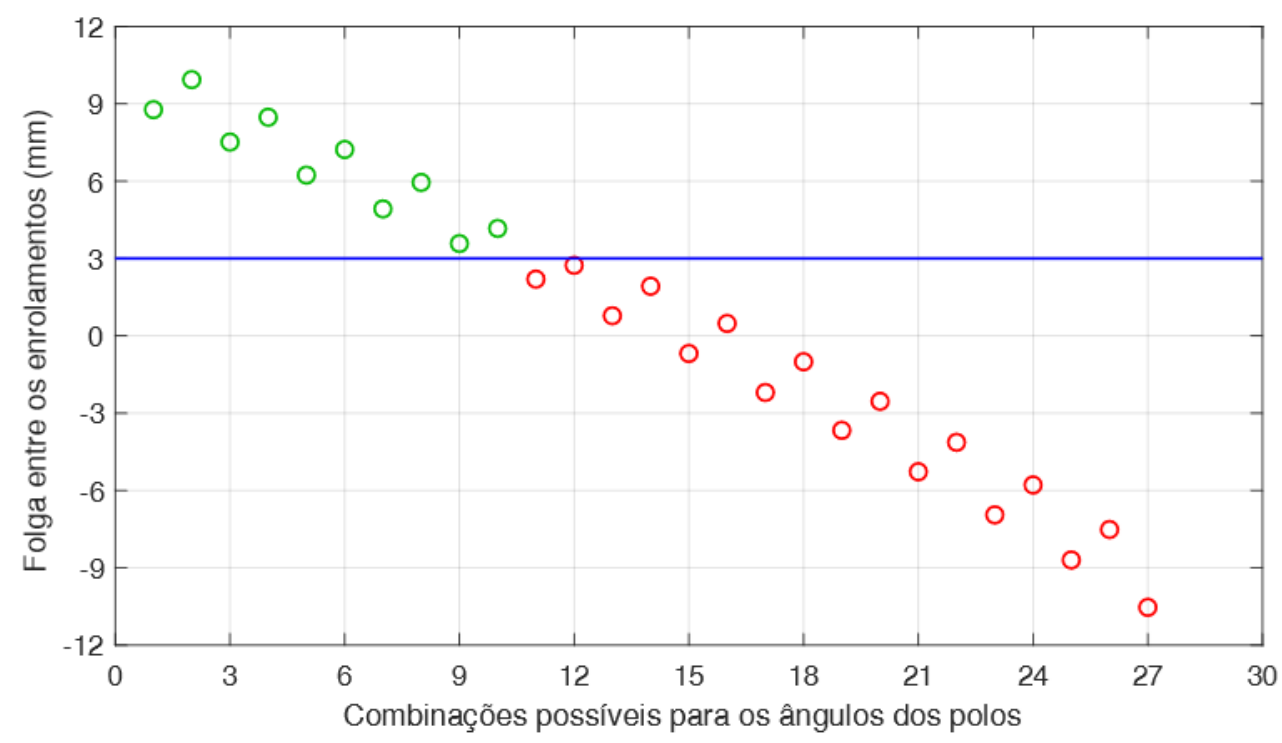

Fonte: Elaboração própria.

Tabela 3. Resultados obtidos nas simulações dos dez motores com combinações de ângulos de polos diferentes.

\begin{tabular}{|c|c|c|c|c|c|c|c|c|c|c|}
\hline Combinação & 1 & 2 & 3 & 4 & 5 & 6 & 7 & 8 & 9 & 10 \\
\hline $\begin{array}{l}\text { Ângulo do polo do } \\
\text { estator }\left(^{\circ}\right)\end{array}$ & 16 & 16 & 17 & 17 & 18 & 18 & 19 & 19 & 20 & 20 \\
\hline $\begin{array}{l}\text { Ângulo do polo do } \\
\text { rotor }\left(^{\circ}\right)\end{array}$ & 17 & 18 & 18 & 19 & 19 & 20 & 20 & 21 & 21 & 22 \\
\hline $\begin{array}{l}\text { Torque médio } \\
\text { (N.m) }\end{array}$ & 5,553 & 4,865 & 5,919 & 5,339 & 6,286 & 5,670 & 6,655 & 6,003 & 7,030 & 6,235 \\
\hline $\begin{array}{l}\text { Torque médio por } \\
\text { volume }\left(\mathrm{N} . \mathrm{m} / \mathrm{m}^{3}\right)\end{array}$ & 5401,3 & 4686,9 & 5483,6 & 4902,3 & 5566,3 & 4979,3 & 5651,3 & 5057,8 & 5740,5 & 5053,5 \\
\hline $\begin{array}{l}\text { Número de espiras } \\
\text { por fase }\end{array}$ & 108 & 98 & 108 & 100 & 108 & 100 & 108 & 100 & 108 & 100 \\
\hline $\begin{array}{l}\text { Folga entre os } \\
\text { enrolamentos }(\mathrm{mm})\end{array}$ & 8,772 & 9,938 & 7,516 & 8,478 & 6,234 & 7,227 & 4,922 & 5,949 & 3,578 & 4,165 \\
\hline $\begin{array}{l}\text { Perdas no cobre do } \\
\text { estator }(W)\end{array}$ & 54,643 & 49,075 & 55,210 & 50,692 & 55,789 & 51,214 & 56,382 & 51,748 & 56,990 & 52,507 \\
\hline
\end{tabular}

Fonte: Elaboração própria.

A análise dos dados da Tabela 3 logo de início decorre na eliminação das combinações 1, 2, 3, 4, 6 e 8; pois resultaram em valores de torque médio menores do que o requerido para o projeto, que é de 6,061 N.m conforme a Tabela 2. As combinações 7 e 9 também podem ser descartadas pois geraram torques muito além do requerido, restando apenas as combinações 5 e 10. Neste momento, é importante analisar as perdas no cobre. Como para a combinação 5 é utilizado um número maior de espiras em comparação com a combinação 10, as perdas no cobre para a mesma são mais elevadas, e é por esse motivo que é escolhida a combinação 10 para o MRV, correspondentes aos ângulos dos polos $\beta_{s}=20^{\circ}$ e $\beta r=22^{\circ}$.

Observa-se na Tabela 3 que o número de espiras por fase $N_{e s p}$ do MRV varia de acordo com cada combinação de $\beta_{s}$ e $\beta r$. Isso ocorre porque o número de espiras é calculado pela divisão entre a força magnetomotriz $\mathfrak{I}$ e a corrente de pico $i_{p}$. 
Como os valores dos ângulos dos polos afetam as dimensões das áreas dos polos e de outras partes do motor, então a $\mathfrak{I}$ gerada varia para cada combinação, o que faz com que $N_{e s p}$ também seja afetado de acordo com os valores selecionados para $\beta$ e e $\beta$ r.

\subsubsection{Cálculo das outras dimensões}

Para limitar o valor máximo da densidade de fluxo magnético Bmax em qualquer parte do motor, foi escolhido o ponto correspondente ao "joelho" da curva BH do aço M-19. De acordo com a curva BH disponível no FEMM, o valor da densidade de fluxo nesse ponto é 1,675 T. Como os polos do estator são as regiões em que ocorrem as maiores densidades de fluxo quando o motor está em operação, adota-se a densidade de fluxo nesse local $B_{s p}=B \max =1,675 \mathrm{~T}$.

Vijayraghavan (2001) relata que para reduzir a emissão de ruídos pelo motor em funcionamento, experiências de projeto mostraram que é importante fixar o valor da densidade de fluxo magnético na culatra do estator $B_{s y} \mathrm{em}$ aproximadamente metade do valor de $B \max$, ou seja, $B s y=0,8375 \mathrm{~T}$; e também fixar a densidade de fluxo magnético na culatra do rotor $B r y$ em torno de $80 \%$ de $B \max$, ou seja, $B_{r y}=1,3400 \mathrm{~T}$. Dessa forma, a densidade de fluxo magnético no polo do rotor $B_{r p}$ é também indiretamente fixada, pois pode ser estimada pelo valor de $B_{s p}$ multiplicado pela razão entre áreas dos polos do estator $A_{s p}$ e do rotor $A_{r p}$, resultando em $B_{r p}=1,5333 \mathrm{~T}$.

A partir dessas atribuições, as dimensões restantes do MRV podem ser obtidas. Sendo $A_{s y}$ a área da culatra do estator, então a largura da culatra do estator $y_{s}$ pode ser calculada pela Equação (9):

$$
y_{s}=\frac{A_{s y}}{L}=\frac{A_{s p}}{L}=\frac{D_{i}}{2} \times \beta_{s}
$$

Com valor de $y_{s}$ obtido, a altura do polo do estator $h_{s}$ é facilmente determinada através da Equação (10):

$$
h_{s}=\frac{D_{o}}{2}-y_{s}-\frac{D_{i}}{2}
$$

Segundo Mamede (2016), para máquinas elétricas com potências superiores a $1 \mathrm{hp}$, o comprimento do entreferro $l g$ deve variar entre $0,3 \mathrm{~mm}$ e $0,5 \mathrm{~mm}$. Para este projeto, optou-se pela escolha de $l_{g}=0,3 \mathrm{~mm}$. Com isso, a altura do polo do rotor $h r$ pode ser calculada a partir da Equação (11):

$$
h_{r}=\frac{D_{i}}{2}\left(1-\frac{\beta_{s}}{1,6}\right)-l_{g}-\frac{D_{s h}}{2}
$$

Finalmente, substituindo o valor de $h_{r}$ na Equação (12), a largura da culatra do rotor $y_{r}$ pode então ser determinada.

$$
y_{r}=\frac{D_{i}}{2}-l_{g}-h_{r}-\frac{D_{s h}}{2}
$$

Para evitar o preenchimento deste artigo com muitas equações, as deduções das Equações (9) e (11) foram omitidas, porém podem ser facilmente encontradas de forma detalhada na tese desenvolvida por Vijayraghavan (2001).

\subsubsection{Projeto dos enrolamentos}

O primeiro passo do projeto dos enrolamentos consiste na determinação do número de espiras por fase, mas para isso é necessário calcular a força magnetomotriz gerada para a posição alinhada, pois é nessa posição que os valores das densidades de fluxo em toda a estrutura do MRV são máximos. Esse cálculo é feito de acordo com os valores pré-fixados para as densidades de fluxo magnético Bfix em cada parte do motor. Para cada valor de Bfix, encontra-se o valor correspondente da intensidade de campo magnético $H_{f i x}$ na curva de magnetização do aço M-19. Assim, com os caminhos médios do fluxo em 
cada secção, aplica-se a lei de Ampère para determinar a $\mathfrak{J}$ total através da Equação (13). Fixando a corrente de pico em 12 A (Vijayraghavan, 2001), Nesp é então calculado pela Equação (14).

$$
\begin{gathered}
\mathfrak{I}=2\left(H_{s p} l_{s p}+H_{g} l_{g}+H_{r p} l_{r p}\right)+\frac{H_{s y} l_{s y}+H_{r y} l_{r y}}{2} \\
N_{e s p}=\frac{\mathfrak{I}}{i_{p}}
\end{gathered}
$$

O cálculo do diâmetro do condutor é feito adotando um limite para a densidade de corrente $J_{c_{-} \max }$ em uma bobina. Para este projeto, esse limite foi de $6 \mathrm{~A} / \mathrm{mm}^{2}$, o que resultou na especificação do fio 16 AWG. Para segurar os condutores nos polos, foram utilizadas cunhas com alturas $h_{\text {wed }}$ de $4 \mathrm{~mm}$. Também foi adotado um fator de ocupação das bobinas $f f$ de 0,75 (Vijayraghavan, 2001). Com base nisso, a folga entre os enrolamentos é então determinada seguindo os cálculos desenvolvidos por Vijayraghavan (2001), encerrando-se o projeto do MRV. As especificações obtidas no projeto estão reunidas na Tabela 4.

Tabela 4. Especificações do MRV 8/6 projetado.

\begin{tabular}{lll}
\hline Parâmetro & Símbolo & Valor \\
\hline Número de polos do estator & $N s$ & 8 \\
Número de polos do rotor & $N r$ & 6 \\
Diâmetro externo do estator & $D o$ & $174 \mathrm{~mm}$ \\
Diâmetro interno do estator & $D i$ & $90 \mathrm{~mm}$ \\
Diâmetro do eixo & $D s h$ & $24 \mathrm{~mm}$ \\
Comprimento da pilha de lâminas & $L$ & $85 \mathrm{~mm}$ \\
Comprimento do entreferro & $l g$ & $0,3 \mathrm{~mm}$ \\
Ângulo do polo do estator & $\beta s$ & $20^{\circ}$ \\
Ângulo do polo do rotor & $\beta r$ & $22^{\circ}$ \\
Altura do polo do estator & $h s$ & $26,3 \mathrm{~mm}$ \\
Altura do polo do rotor & $h r$ & $22,9 \mathrm{~mm}$ \\
\hline Largura da culatra do estator & $y s$ & $15,7 \mathrm{~mm}$ \\
Largura da culatra do rotor & $y r$ & $9,8 \mathrm{~mm}$ \\
\hline Condutor & $\varnothing$ & $16 \mathrm{AWG}$ \\
Número de espiras por fase & $N e s p$ & 100 \\
Altura das cunhas & $h w e d$ & $4 \mathrm{~mm}$ \\
Folga entre os enrolamentos & $C l$ & $4,2 \mathrm{~mm}$ \\
\hline
\end{tabular}

Fonte: Elaboração própria.

\section{Resultados e Discussão}

\subsection{Análise da densidade de fluxo magnético}

Durante a etapa de dimensionamento do MRV foram fixados valores máximos de densidade de fluxo magnético para o polo do estator, para a culatra do estator e para a culatra do rotor. A densidade de fluxo magnético no polo do rotor também foi indiretamente fixada, pois pode ser estimada pela proporção entre as áreas dos polos do estator e rotor. Para comparar os valores estipulados com os valores simulados, é aplicada a corrente de pico de 12 A no modelo do MRV implementado no 
FEMM. Os valores máximos são obtidos para a posição alinhada (Figura 7) e são reunidos na Tabela 5. Os dados apresentados na Tabela 5 revelam a precisão da metodologia de projeto utilizada neste trabalho. Os erros relativos calculados foram mínimos. Para fim de visualização também é simulado o motor na posição desalinhada (Figura 8).

Figura 7. Densidade de fluxo magnético na estrutura do MRV 8/6 para a posição alinhada.
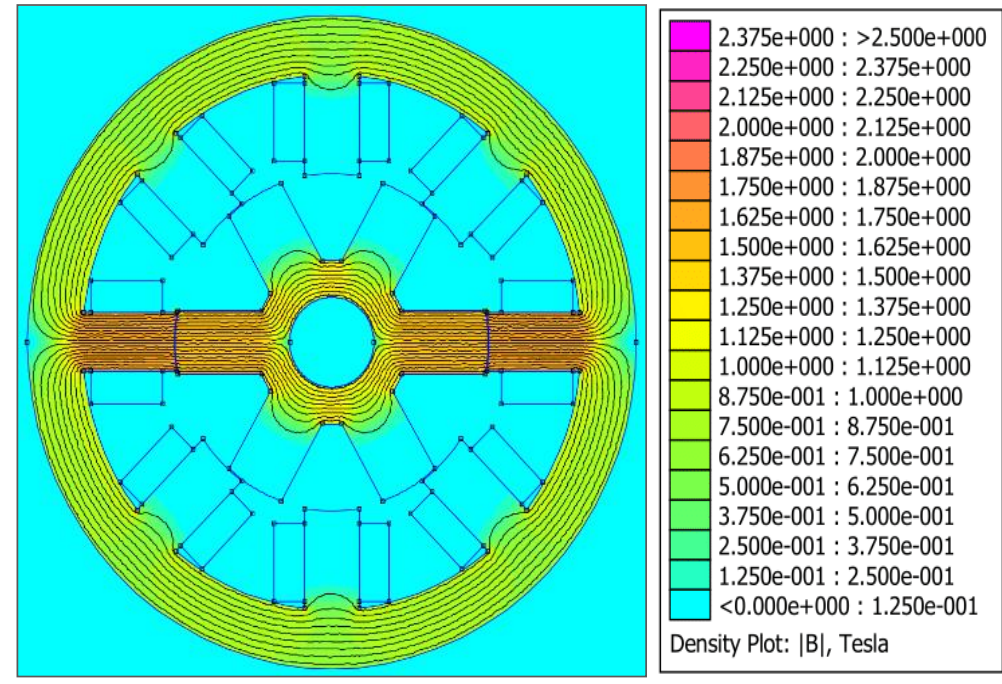

Fonte: Elaboração própria.

Figura 8. Densidade de fluxo magnético na estrutura do MRV 8/6 para a posição desalinhada.

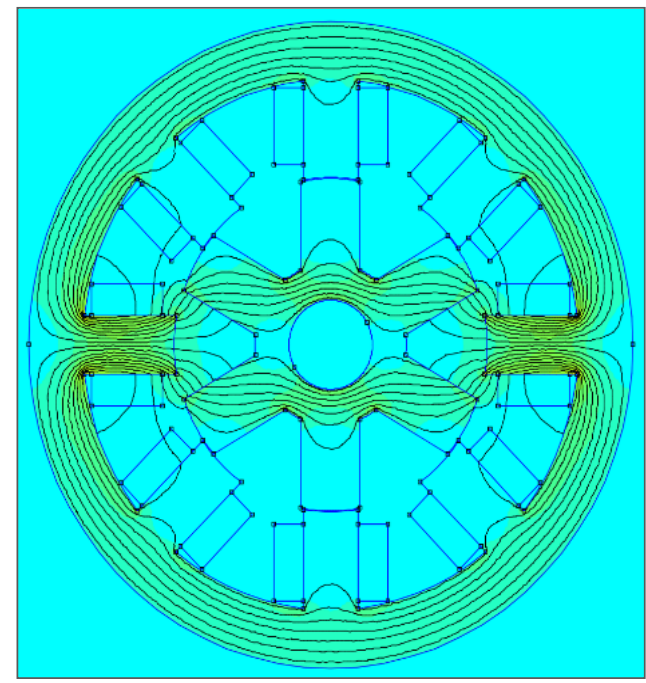

$9.500 \mathrm{e}-001:>1.000 \mathrm{e}+000$

$9.000 \mathrm{e}-001: 9.500 \mathrm{e}-001$

$8.500 \mathrm{e}-001: 9.000 \mathrm{e}-001$

$8.000 \mathrm{e}-001: 8.500 \mathrm{e}-001$

$7.500 \mathrm{e}-001: 8.000 \mathrm{e}-001$

$7.000 \mathrm{e}-001: 7.500 \mathrm{e}-001$

$6.500 \mathrm{e}-001: 7.000 \mathrm{e}-001$

$6.000 \mathrm{e}-001: 6.500 \mathrm{e}-001$

$5.500 \mathrm{e}-001: 6.000 \mathrm{e}-001$

$5.000 \mathrm{e}-001: 5.500 \mathrm{e}-001$

$4.500 \mathrm{e}-001: 5.000 \mathrm{e}-001$

$4.000 \mathrm{e}-001: 4.500 \mathrm{e}-001$

$3.500 \mathrm{e}-001: 4.000 \mathrm{e}-001$

$3.000 \mathrm{e}-001: 3.500 \mathrm{e}-001$

$2.500 \mathrm{e}-001: 3.000 \mathrm{e}-001$

$2.000 \mathrm{e}-001: 2.500 \mathrm{e}-001$

$1.500 \mathrm{e}-001: 2.000 \mathrm{e}-001$

$1.000 \mathrm{e}-001: 1.500 \mathrm{e}-001$

5.000e-002: $1.000 \mathrm{e}-001$

$<0.000 \mathrm{e}+000: 5.000 \mathrm{e}-002$

Density Plot: $|\mathrm{B}|$, Tesla

Fonte: Elaboração própria. 
Tabela 5. Valores máximos estipulados e simulados para as densidades de fluxo magnético nas várias regiões da estrutura do MRV 8/6.

\begin{tabular}{llll}
\hline \multirow{2}{*}{ Região } & \multicolumn{2}{l}{ Densidade de fluxo magnético } & \multirow{2}{*}{ Erro relativo } \\
& Valor estipulado & Valor simulado & \\
\hline Polo do estator & 1,6750 & 1,7038 & $1,6903 \%$ \\
Polo do rotor & 1,5333 & 1,5213 & $0,7888 \%$ \\
Culatra do estator & 0,8375 & 0,8444 & $0,8171 \%$ \\
Culatra do rotor & 1,3400 & 1,3469 & $0,5123 \%$ \\
\hline
\end{tabular}

Fonte: Elaboração própria.

\subsection{Obtenção das curvas de fluxo magnético concatenado e indutância, e cálculo do torque do MRV}

Para otimizar o processo de simulação, desenvolveu-se um código na linguagem Lua Script, que permite a interação com o FEMM. Esse código foi responsável por fazer a movimentação do rotor da posição desalinhada $\left(\theta=-30^{\circ}\right)$, passando pela posição alinhada $\left(\theta=0^{\circ}\right)$, até novamente atingir outra posição desalinhada $\left(\theta=30^{\circ}\right)$, completando um ciclo elétrico de operação. Também foi feita a variação da corrente de uma das fases de 1 A à 12 A para cada posição do rotor, salvando os valores de fluxo concatenado e indutância, correspondentes a cada posição e corrente aplicada. Os gráficos resultantes estão mostrados nas Figuras 9 e 10.

Figura 9. Perfil de fluxo magnético concatenado em função da corrente de excitação e da posição do rotor para um ciclo elétrico do MRV 8/6 projetado.

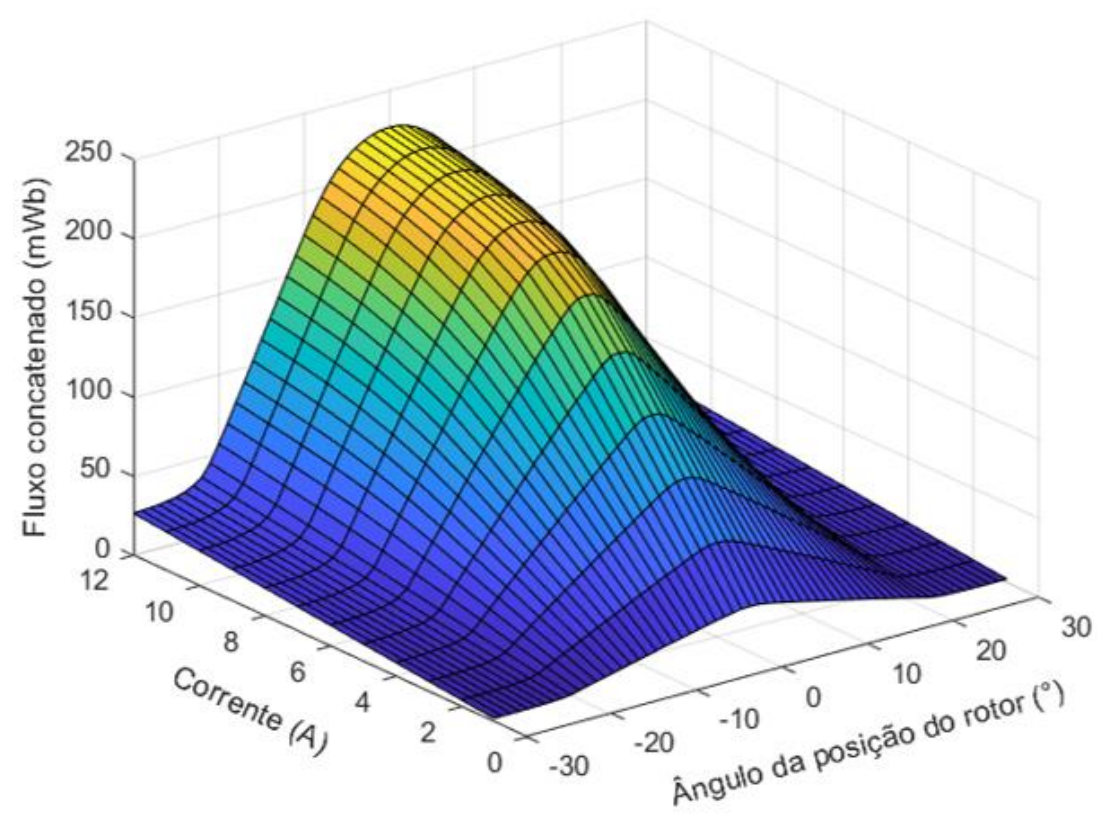

Fonte: Elaboração própria. 
Figura 10. Perfil de indutância em função da corrente de excitação e da posição do rotor para um ciclo elétrico do MRV 8/6 projetado.

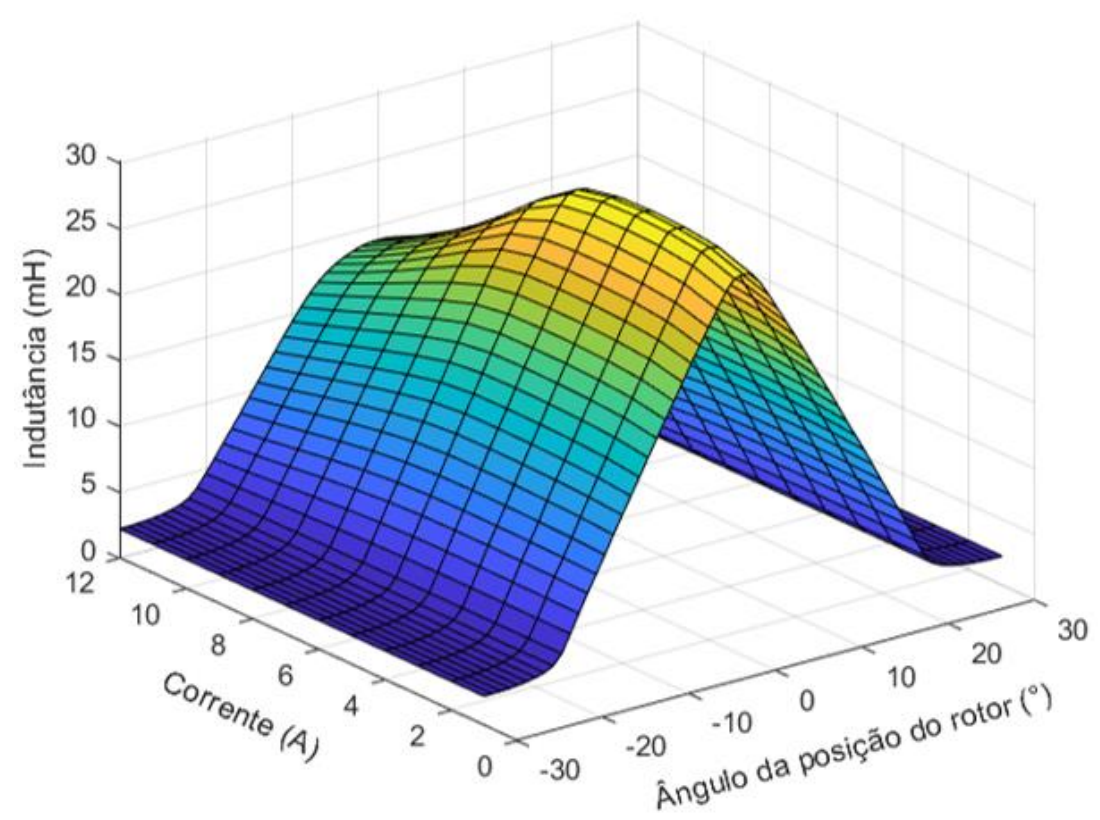

Fonte: Elaboração própria.

Com base nos dados resultantes da simulação, calcula-se também o torque médio do motor, utilizando o procedimento explicado na seção 2 deste artigo. O gráfico obtido para o protótipo projetado, que destaca o comportamento do fluxo versus corrente para as posições alinhada e desalinhada, é mostrado na Figura 11. A partir desse gráfico são calculados os valores das coenergias e do torque, que estão apresentados na Tabela 6, juntamente com os dados de fluxo concatenado e indutância obtidos na simulação do FEMM para as duas posições do rotor.

Figura 11. Fluxo magnético concatenado versus corrente para as posições alinhada e desalinhada do rotor do MRV 8/6 projetado.

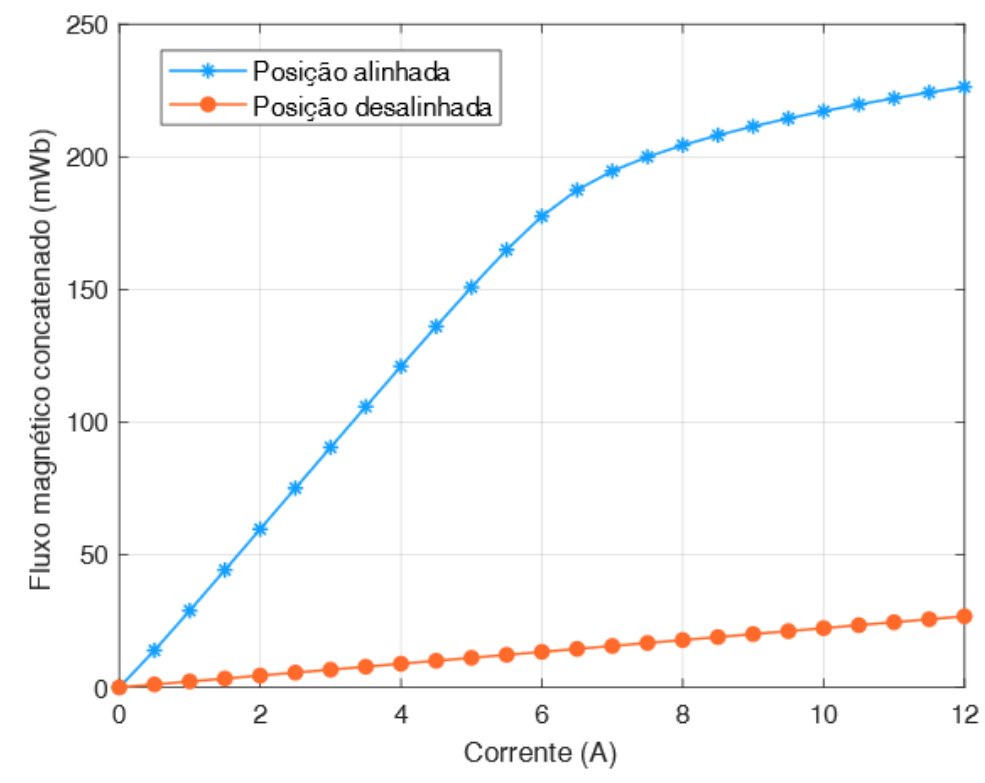

Fonte: Elaboração própria. 
Tabela 6. Resultados obtidos a partir da análise de elementos finitos para o MRV 8/6 projetado.

\begin{tabular}{lll}
\hline Parâmetro & Símbolo & Valor \\
\hline Fluxo concatenado para a posição alinhada & $\lambda a$ & $226,3631 \mathrm{mWb}$ \\
Fluxo concatenado para a posição desalinhada & $\lambda d$ & $26,8250 \mathrm{mWb}$ \\
Indutância para a posição alinhada & $L a$ & $18,8636 \mathrm{mH}$ \\
Indutância para a posição desalinhada & $L d$ & $2,2354 \mathrm{mH}$ \\
Coenergia para a posição alinhada & $W^{\prime} a$ & 1,7929 u.e. \\
Coenergia para a posição desalinhada & $W^{\prime} d$ & 0,1606 u. e. \\
Torque médio calculado & $T m$ & 6,2348 N.m \\
\hline
\end{tabular}

Fonte: Elaboração própria.

A análise dos gráficos das Figuras 9 e 10 demonstra que as curvas obtidas possuem comportamentos coerentes com o previsto pela teoria de MRVs. Tanto a indutância quanto o fluxo magnético tiveram seus valores reduzidos ao girar o rotor para uma posição diferente de $0^{\circ}$ e esse decaimento ocorreu gradativamente até a posição de $30^{\circ}$, onde o valor da relutância equivalente do circuito magnético da máquina é máxima. Já ao variar a corrente para uma determinada posição fixa, percebe-se que o valor do fluxo concatenado aumenta e o valor da indutância diminui com o incremento da corrente.

O resultado obtido para o torque médio do MRV, apresentado na Tabela 6, está de acordo com o valor esperado para o projeto, sendo ligeiramente superior ao do MIT mostrado na Tabela 2, o que pode ser considerado bom, pois possibilitará um pequeno acréscimo de carga quando o motor estiver em funcionamento.

\section{Conclusão}

Neste artigo, um MRV 8/6 tetrafásico foi projetado e analisado. As dimensões deste motor foram calculadas de forma que fosse possível aproveitar a mesma carcaça já disponível de um motor de indução trifásico, que será substituído pelo MRV. A metodologia de projeto utilizada, aliada às simulações por elementos finitos, possibilitou alcançar um dimensionamento final otimizado, que resultou em características eletromagnéticas satisfatórias para o protótipo projetado. Os valores das densidades de fluxo magnético obtidos nas simulações realizadas no FEMM foram muito próximos dos valores estipulados na etapa de dimensionamento, sendo o maior erro de 1,69\%. As curvas obtidas de fluxo concatenado e indutância apresentaram comportamentos coerentes com o esperado para esse tipo de motor. O torque médio obtido para o protótipo do MRV está de acordo com o valor requerido para o projeto, sendo ligeiramente superior ao do motor de indução trifásico.

Em suma, os resultados apresentados por este estudo sustentam que o procedimento de projeto utilizado é eficiente e pode ser empregado para o desenvolvimento de outros MRVs com diferentes topologias. Em trabalhos futuros baseados neste artigo o foco será na comparação dos resultados simulados com resultados experimentais, que serão obtidos após a construção física do protótipo e a implementação do seu sistema de acionamento. Com isso, será possível realizar estudos comparativos de desempenho do MRV em relação a outros tipos de motores. Análises térmicas, de vibrações mecânicas e de ruído acústico também serão objetivos de estudos.

\section{Agradecimentos}

Os autores agradecem à Coordenação de Aperfeiçoamento de Pessoal de Nível Superior (CAPES), ao Conselho Nacional de Desenvolvimento Científico e Tecnológico (CNPq) e à Fundação de Amparo à Pesquisa do Estado de Minas Gerais (FAPEMIG) pelo apoio financeiro que foi essencial para o desenvolvimento da pesquisa. 


\section{Referências}

Ahn, J. W., \& Lukman, G. F. (2018). Switched reluctance motor: Research trends and overview. CES Transactions on Electrical Machines and Systems, 2(4), 339-347. 10.30941/CESTEMS.2018.00043

Bilgin, B., \& Emadi, A. (2018). Electric motor industry and switched reluctance machines. In Switched Reluctance Motor Drives (pp. 1-33). CRC Press.

Castellini, L., Lucidi, S., \& Villani, M. (2015). Design optimization of switched reluctance motor for aerospace application. 2015 IEEE International Electric Machines \& Drives Conference (IEMDC), 1678-1682. 10.1109/IEMDC.2015.7409289

Chiba, A., \& Kiyota, K. (2015). Review of research and development of switched reluctance motor for hybrid electrical vehicle. 2015 IEEE Workshop on Electrical Machines Design, Control and Diagnosis (WEMDCD), 127-131. 10.1109/WEMDCD.2015.7194520

Howey, B., \& Li, H. (2018). Operational principles and modeling of switched reluctance machines. In Switched Reluctance Motor Drives (pp. 123-181). CRC Press.

Hutton, D. V. (2004). Basic concepts of the finite element method. In Fundamentals of Finite Element Analysis (pp. 1-18). McGraw Hill.

Jiang, W. (2016). Three-phase 24/16 switched reluctance machine for hybrid electric powertrains: Design and optimization (Doctoral thesis). McMaster University, Hamilton, ON, Canada.

Krishnan, R. (2001). Switched reluctance motor drives: modeling, simulation, analysis, design, and applications. CRC Press.

Lu, M. Z., Jhou, P. H., \& Liaw, C. M. (2020). Wind switched-reluctance generator based microgrid with integrated plug-in energy support mechanism. IEEE Transactions on Power Electronics, 36(5), 5496-5511. 10.1109/TPEL.2020.3029528

Mamede, A. C. F. (2016). Projeto iterativo, simulação, análise e otimização de máquina a relutância variável monofásica (Dissertação de mestrado). Universidade Federal de Uberlândia, Uberlândia, MG, Brasil.

Mamede, A. C. F., Camacho, J. R., \& Araújo, R. E. (2020). Review of rotary switched reluctance machine design and parameters effect analysis. In Modelling and Control of Switched Reluctance Machines (pp. 59-80). IntechOpen. 10.5772/intechopen.92409

Meeker, D. (2020). Finite element method magnetics (FEMM). Ver. 4.2 User's Manual.

Miller, T. J. E. (Ed.). (2001). Electronic control of switched reluctance machines. Elsevier.

Oliveira, V. S. (2013). Aplicação do método dos elementos finitos 3D na caracterização eletromagnética estática de motores de relutância variável com validação experimental (Dissertação de mestrado). Universidade Federal do Ceará, Fortaleza, CE, Brasil.

Pyrhonen, J., Jokinen, T., \& Hrabovcova, V. (2013). Properties of rotating electrical machines. In Design of rotating electrical machines (pp. 479-492). John Wiley \& Sons.

Rahmanian, E., Akbari, H., \& Sheisi, G. H. (2017). Maximum power point tracking in grid connected wind plant by using intelligent controller and switched reluctance generator. IEEE Transactions on Sustainable Energy, 8(3), 1313-1320. 10.1109/TSTE.2017.2678679

Viajante, G.P., Chaves, E.N., Freitas, M.A., Domingos, J.L., Fidelis, R.T., Gomes, L.C., \& Andrade, D.A. (2018). Study and dynamic performance analysis of a switched reluctance generator 8/6 for wind energy application. 2018 IEEE International Conference on Environment and Electrical Engineering and 2018 IEEE Industrial and Commercial Power Systems Europe (EEEIC / I\&CPS Europe), 1-6. 10.1109/EEEIC.2018.8493726

Vijayraghavan, P. (2001). Design of switched reluctance motors and development of a universal controller for switched reluctance and permanent magnet brushless DC motor drives (Doctoral dissertation). Virginia Polytechnic Institute and State University, Blacksburg, VA, United States of America.

Watthewaduge, G., Sayed, E., Emadi, A., \& Bilgin, B. (2020). Electromagnetic modeling techniques for switched reluctance machines: State-of-the-art review. IEEE Open Journal of the Industrial Electronics Society, 1, 218-234. 10.1109/OJIES.2020.3016242

WEG S. A. (2021). W22 Motor Elétrico Trifásico - Catálogo Técnico Mercado Brasil (pp. 36 e 42-43). https://static.weg.net/medias/downloadcenter/h94/h69/WEG-w22-motor-eletrico-trifasico-50023622-brochure-portuguese-web.pdf. 